\title{
50 \\ Group Polarization in the Team Dictator Game reconsidered
}

\author{
Wolfgang J. Luhan' \\ Martin G. Kocher ${ }^{2}$ \\ Matthias Sutter ${ }^{3}$
}

1 University of Innsbruck,

2 Universiteit van Amsterdam, and Tinbergen Institute

3 University of Cologne. 


\section{Tinbergen Institute}

The Tinbergen Institute is the institute for economic research of the Erasmus Universiteit Rotterdam, Universiteit van Amsterdam, and Vrije Universiteit Amsterdam.

Tinbergen Institute Amsterdam

Roetersstraat 31

1018 WB Amsterdam

The Netherlands

Tel.: $\quad+31(0) 205513500$

Fax: $\quad+31(0) 205513555$

Tinbergen Institute Rotterdam

Burg. Oudlaan 50

3062 PA Rotterdam

The Netherlands

Tel.: $\quad+31(0) 104088900$

Fax: $\quad+31(0) 104089031$

Most TI discussion papers can be downloaded at http:/ /www.tinbergen.nl. 


\title{
Group polarization in the team dictator game
}

\section{reconsidered $^{*}$}

\author{
Wolfgang J. Luhan ${ }^{\ddagger}$, Martin G. Kocher ${ }^{\dagger}$, and Matthias Sutter $^{+}$
}

\begin{abstract}
While most papers on team decision-making find teams to behave more selfish, less trusting and less altruistic than individuals, Cason and Mui (1997) report that teams are more altruistic than individuals in a dictator game. Using a within-subjects design we reexamine group polarization by letting subjects make individual as well as team decisions in an experimental dictator game. In our experiment teams are more selfish than individuals, and the most selfish team member has the strongest influence on team decisions. Various sources of the different findings in Cason and Mui (1997) and in our paper are discussed.
\end{abstract}

JEL classification: C72, C91, C92, D70

Keywords: experiment, dictator game, team behavior, social preferences

This version: 8 August 2006

\footnotetext{
${ }^{*}$ We would like to thank Tim Cason for very helpful comments. Financial support from the Austrian Science Foundation (FWF Project P16617) and the Center for Experimental Economics at the University of Innsbruck (sponsored by Raiffeisen-Landesbank Tirol) is gratefully acknowledged.

$\$$ University of Innsbruck, Department of Economics, Universitaetsstrasse 15/4, A-6020 Innsbruck, Austria. Email: wolfgang.luhan@uibk.ac.at.

${ }^{\dagger}$ Corresponding author. University of Amsterdam, Department of Economics, CREED, Roetersstraat 11, NL1018 WB Amsterdam, Netherlands. Email: martin.kocher@uibk.ac.at.

${ }^{+}$University of Cologne, Department of Economics, Albertus-Magnus-Platz, D-50923 Köln, Germany. Email: msutter@uni-koeln.de.
} 


\section{Introduction}

Team decision-making has attracted more and more interest among economists in recent years. Although the standard models of economic theory largely neglect the type of the decision maker by simply assuming individual decision-making, many economic decisions are made by teams, such as families, company boards, management teams, committees, or central bank boards. One of the key requirements of team decision-making is the need to aggregate individual preferences into one single team decision.

In this paper we will examine the aggregation of social preferences in an experimental team dictator game. This simple game isolates pure distributional concerns from any strategic considerations that shape bargaining behavior, for instance, in the well-known ultimatum game (Güth et al., 1982). ${ }^{1}$ Hence, using the dictator game allows us to investigate how individual preferences with respect to the allocation of money between a dictator and a (powerless) recipient are transformed into a team decision.

In general, the experimental literature on unitary team ${ }^{2}$ behavior in simple bargaining games is rather coherent in its finding that team decisions are typically closer to standard game theoretic predictions than individual decisions, that teams seem to be stronger motivated by payoff maximization and that their decisions are more selfish. For example, teams have been found to send and accept smaller transfers in the ultimatum game (Bornstein and Yaniv, 1998), send or return smaller amounts in the trust game (Cox, 2002; Kugler et al., 2006),

\footnotetext{
${ }^{1}$ Forsythe et al. (1994) used the dictator game in order to study which share of the transfers observed in the ultimatum game can be explained by pure altruistic motivation. By removing the responder's option to reject the proposer's offer, any strategic reason for generous offers in the dictator game is eliminated, thus leaving only social preferences, such as altruism, warm glow or inequality aversion, as possible explanations.

${ }^{2}$ With „unitary“ teams we denote teams that face no internal conflict in terms of payoff and that have to come up with a single team decision. All related studies share this feature of decision-making within teams.
} 
choose lower efforts as second movers in a gift-exchange game (Kocher and Sutter, 2006; Brosig et al., 2006), play more strategically and more often according to theoretic predictions in signaling games (Cooper and Kagel, 2005), exit the centipede game at earlier stages (Bornstein et al., 2004), make more rational decisions in intellective tasks, such as the Wason selection task (Maciejovsky and Budescu, 2005), and gain a higher payoff/risk ratio in investment games (Rockenbach et al., 2006). In auctions teams display much more competitive bidding behavior, leading to higher rates of overbidding (Cox and Hayne, 2006; Sutter et al., 2005).

In contrast to this large body of evidence Cason and Mui (1997) find teams to be more altruistic and other-regarding than individuals. In their experimental dictator game each subject has to make two decisions on the allocation of five dollars, once individually and once in a two-person team. Cason and Mui (1997) show that team decisions are driven by the more altruistic team member. They conclude that "this makes team choices more other-regarding than individual choices for these teams, although the difference is modest" (p. 1480). More precisely, individuals transfer on average $26.09 \%$ of their endowment to the receiver, compared to the $27.61 \%$ of teams. Cason and Mui (1997) explain this effect by recurring to "Social Comparison Theory" (SCT). SCT states that subjects have a tendency to appear and present themselves in teams in a way that is deemed socially desirable. After having observed other subjects' behavior or choices or after having discussed the possible options in a game, the own behavior is modified to appear more in line with the perceived social norms. If otherregarding behavior is socially desirable, then team decisions can be expected to be more other-regarding than individual decisions. ${ }^{3}$

\footnotetext{
${ }^{3}$ Cason and Mui (1997) reject "Persuasive Argument Theory" (PAT) as a possible explanation for their data. The bottom-line of PAT is that group discussion is able to shift choices in favor of the pre-discussion or initial tendency by a higher attentiveness towards more persuasive arguments in favor of one's initial position. Both theories, SCT and PAT, have their roots in the psychological discussion of "group
} 
Though (or perhaps because) the results of Cason and Mui (1997) do not fit the overall picture emerging from team decision experiments, they have been frequently cited and are widely accepted as a notable exception in the evidence on team decision-making (see, for example, Bosman and van Winden, 2002; Andreoni and Petrie, 2004; Bornstein et al., 2004; Cooper and Kagel, 2005; Kocher and Sutter, 2005; Dufwenberg and Muren, 2006). Given the prominence that the results of Cason and Mui (1997) have achieved and since we consider replications of results important in experimental economics, this paper examines the robustness of Cason and Mui's (1997) findings. Moreover, it adds some interesting new insights on the decision-making process within teams.

We are not aware of any attempt to replicate the findings of Cason and Mui (1997). ${ }^{4}$ The most closely related paper - as far as team decision-making in the dictator game is concerned - is by Dufwenberg and Muren (2006). They study the influence of a team's gender composition on decisions in the following dictator game. A team of three subjects has to allocate 1000 Swedish kronor (110\$ at that time) among the three team members and a fourth person. Teams send on average $21.83 \%$ of the pie to the fourth person, keeping $26.06 \%$ for each team member ${ }^{5}$. Out of the four possible gender compositions of a three-person team, Dufwenberg and Muren (2006) find female dominated teams to allocate significantly higher amounts to the fourth person, with teams of two women and one man sending the highest amounts. Though their study examines team behavior in the dictator game, it does not provide a comparison of team and individual behavior, which is the focus of our paper.

polarization" (see e.g., Moscovici and Zavalloni, 1969; Davis, 1992; Kerr et al., 1996; Levine and Moreland, 1998).

${ }^{4}$ Note, of course, that second movers in a trust game are basically in the situation of a dictator, as they can determine the final distribution of money between the first and the second mover. The evidence from Cox (2002) clearly indicates that teams are more selfish as second movers than individuals.

${ }^{5}$ As dictators had a small, but positive chance (of about $1.7 \%$ ) of ending up in the role of a receiver, offers above 250 are rather due to strategic concerns than pure mistakes or altruism. 
The paper is organized in the following way: We describe our experimental design and procedure in section 2. Section 3 presents the experimental results. Section 4 discusses our findings and concludes.

\section{Experimental design and procedure}

The dictator game was first introduced by Kahnemann et al. (1986) in an empirical study on fairness in the market place. In this game a dictator decides on the distribution of a given stake between himself and a second party, the receiver. The second party has no other option than to take whatever the dictator allocates to her.

In our experiment participants were randomly assigned to the role of either dictator or receiver ${ }^{6}$. These roles were fixed throughout the experiment. Subjects in the role of dictator received $5 €$ as their endowment in each of the following three stages.

- Stage S1: Each subject in the role of dictator decides individually on the transfer $T$ to an individual receiver, where $T \in\{0.0,0.1,0.2, \ldots, 4.9,5.0\}$.

- Stage S2: Each subject in the role of dictator is a member of a team with three persons. Each team has to make a single decision on the transfer $T$ to a receiver team that also consists of three subjects. The per-capita-incentives are kept identical in all stages, such that in stage S2 each team member in the role of dictator earns 5-T€, and each team member in the role of receiver earns $T €$.

- Stage S3: Each subject in the role of dictator has to make a second individual decision with the same rules as in stage S1.

Note that participants were only informed about the next stage after all decisions in a respective stage had been taken. Hence, the first individual decision cannot have been

\footnotetext{
${ }^{6}$ Since we could expect receivers to earn only little money, they were invited to participate in an individual decision-making experiment after the dictator experiment had been finished.
} 
influenced by the subsequent team decision or the second individual decision. Furthermore, we used a publicly announced perfect stranger design throughout the three stages, meaning that no dictator was ever paired with a particular receiver more than once.

An important feature of our design is the assignment of individuals into teams. First of all, we have opted for teams of three subjects each in order to catch Cason and Mui's (1997) suggested extension of checking whether their empirical findings generalize when the size of teams gets larger (p. 1480). Second, we have used the individual stage S1-choices as an instrument to set up heterogeneous groups in a systematic way. Based on their stage S1decision we have classified subjects into terciles. Those in the lowest tercile are the "most selfish" subjects, those in the highest tercile the "most other-regarding", and those in the middle the "moderate" subjects. Within each tercile, subjects are ranked in ascending order according to their individual transfer in stage S1. Each team then consists of the three members with the same rank in each of the three terciles. This procedure guarantees that all teams are very similar with respect to the within-team heterogeneity concerning individual transfers from stage S1. It will allow us to straightforwardly track down the influence of the most selfish, the moderate, or the most other-regarding member on the final team decision.

In order to gain further insights into the process of aggregating individual preferences and into the structure of team discussions, the communication within each team was possible exclusively via an electronic chat program with protocols being stored for later analysis ${ }^{7}$. Subjects were requested to agree on a joint (unanimous) decision within ten minutes. As soon as a team had reached an agreement, each member had to type in this decision on his own screen. Note that we did not specify how teams had to arrive at a joint decision. Even though the inputs of all three members had to be identical to be valid - otherwise the team would not

\footnotetext{
${ }^{7}$ The content of messages within a team was not restricted, except for forbidding abusive language and revealing one's identity (through seat number, name, gender, age, courses taken, etc.). See the experimental instructions in the appendix for details.
} 
have been paid for this stage (what never happened, actually ${ }^{8}$ ) - some teams argued in the chat that a simple majority in case of no unanimous agreement would be sufficient and the third member would have to abide by the majority in such a case. Of course, there was no possibility to enforce such a within-team agreement.

At the end of the experiment we gathered data on subjects' gender, allowing us to examine the influence of gender and gender composition on individual and team decisions. The experiment was run computerized (using z-Tree; Fischbacher, 1999) with 180 students from the University of Innsbruck from various backgrounds. We ran 10 experimental sessions à 18 subjects, yielding 180 observations on individual decision-making (90 in stage S1 and 90 in stage S3) and 30 observations from teams along with concomitant chat-protocols (from stage S2).

\section{Results}

Table 1 shows the main indicators with respect to the chosen transfers. In stage S1 individuals send on average $0.94 €$ to the receiver, i.e. $19 \%$ of the endowment. ${ }^{9}$ The modal transfer (of about one third of subjects) is zero.

The transfers of teams in stage S2 are significantly smaller than those of individuals in stage S1 $(p<0.01$; Wilcoxon signed ranks test; $N=30)$. Teams transfer only $0.54 €$ or about $11 \%$ of their endowment. The maximum transfer is $1.5 €$ out of $5 €$, and 12 out of 30 teams transfer zero.

It turns out that the experience of team decision-making even carries over to individual decisions in stage S3. The transfers in S3 amount, on average, to $0.66 €$ (or about $13 \%$ ) and

\footnotetext{
${ }^{8}$ The instructions specified that in such a case the transfer to the paired team would have been determined randomly.

${ }^{9}$ This average is well within the range of transfers (10\% to $\left.23 \%\right)$ reported in the survey on experimental dictator games by Camerer (2003).
} 
are significantly smaller than individual transfers in S1 $(p<0.01$; Wilcoxon signed ranks test; $N=90)$, but not significantly different from the team decisions in stage $\mathrm{S} 2(p>0.5)$. These results indicate that the experience of team decision-making causes a shift in individually preferred allocations in a dictator game.

Table 1. Transfers in the dictator game

\begin{tabular}{lccc}
\hline & $\begin{array}{c}\text { Stage } \mathrm{S} 1(N=90) \\
\mathbf{1}^{\text {st }} \text { individual transfer }\end{array}$ & $\begin{array}{c}\text { Stage } \mathrm{S} 2(N=30) \\
\text { Team transfer }\end{array}$ & $\begin{array}{c}\text { Stage } \mathrm{S} 3(N=90) \\
\mathbf{2}^{\text {nd }} \text { individual transfer }\end{array}$ \\
\hline Average transfer $T$ & $0.94^{*, \#}$ & $0.54^{*}$ & $0.66^{\#}$ \\
Standard deviation & 1.07 & 0.56 & 0.85 \\
Mode = Minimum & 0.00 & 0.00 & 0.00 \\
Relative frequency of & $34.4 \%$ & $40.0 \%$ & $46.7 \%$ \\
Mode = Minimum & 5.0 & 1.5 & 2.5 \\
Maximum & $1.1 \%$ & $13.3 \%$ & $8.9 \%$ \\
Relative frequency of & Maximum & & \\
* significantly different at $\mathrm{p}<0.01$. & & \\
\# significantly different at $\mathrm{p}<0.01$. &
\end{tabular}

Figure 1 sheds more light on the influence of team decision-making on subsequent individual decisions. It shows for a given subject on the horizontal axis the decision in stage S1 and on the vertical axis the decision in stage S3. Observations below the diagonal indicate a decrease of transfers from S1 to S3. Individuals are classified according to the relation between the team's decision in stage S2 and the first individual decision in stage S1. Note that when the team decision is larger than (see "+" in the figure) or equal to the first individual decision in stage S1 (see "○”), then there is no systematic effect of the team decision on the subsequent individual decision in stage S3. However, if the team decision is smaller than the S1-decision (see "-") individuals reduce their transfer from S1 to S3 in almost all cases, indicated by the "- " under the 45-degree line. The latter result implicates a strong influence of team decision-making on individual decisions if the team decision is more selfish than the initial individual decision, rendering the subsequent individual decision also more selfish. 
Individual decisions S3 vs. S1. (multiple observations indicated)

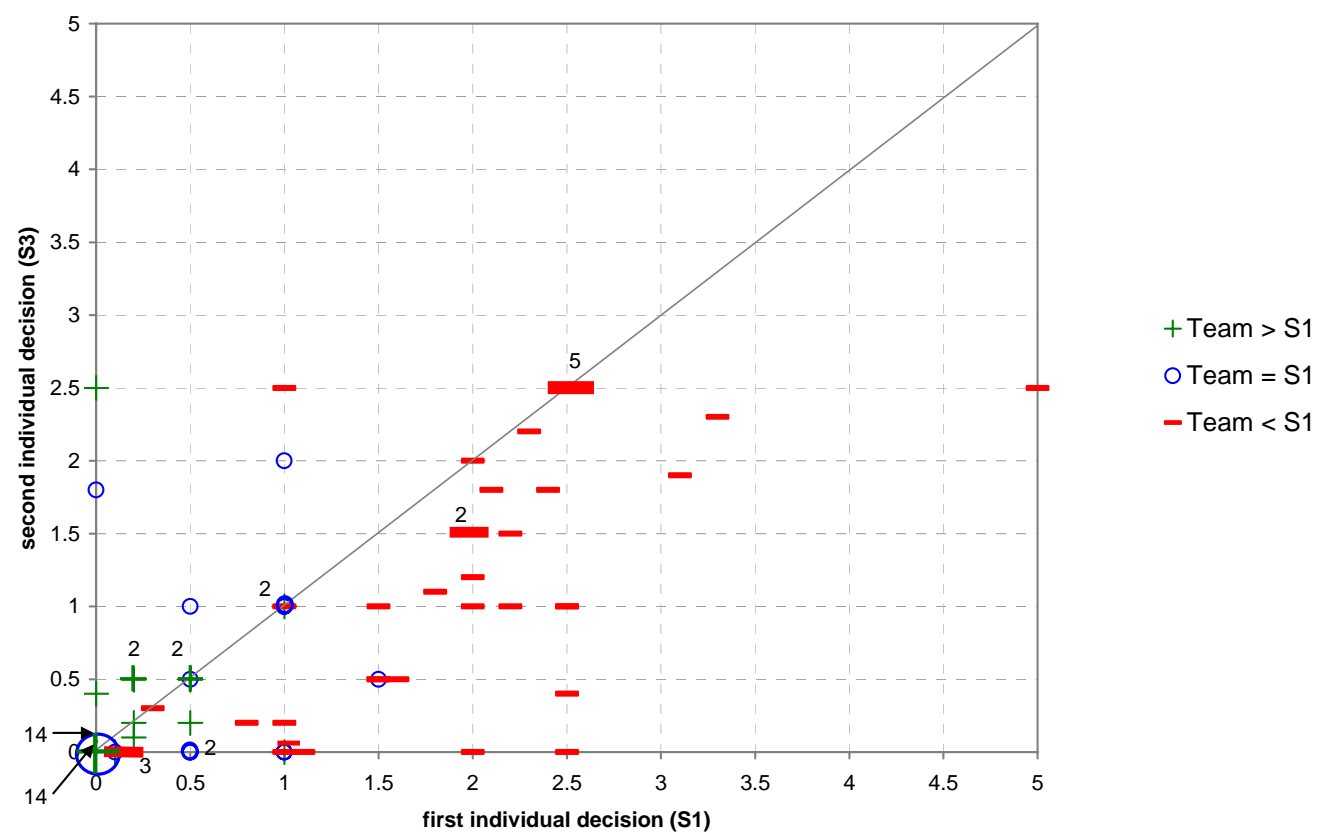

Figure 1. Changes of individual decisions contingent on team decision

Next we examine the process of team decision-making. We have estimated a linear model explaining a team's transfer in S2 as a function of its members' individual transfers in the preceding stage $\mathrm{S} 1 .^{10}$

The results are summarized in Table 2 . The "most selfish" team member (i.e. the team member with the lowest transfer in S1) has by far the largest and in particular the only significant impact on the team transfer. The lower the "most selfish" member's transfer in S1, the lower is the team transfer in S2. This finding is in contrast to the evidence from Cason and Mui (1997) who have found that the team transfer is driven by the most other-regarding member.

\footnotetext{
${ }^{10}$ Using a censored Tobit model yields practically the same results.
} 
Table 2. OLS estimates for team transfers

\begin{tabular}{lcc}
\hline Dependent variable: team transfer & Coefficient & $\begin{array}{c}\text { Robust standard } \\
\text { errors }\end{array}$ \\
\hline Transfer of "most selfish" member in stage S1 & $1.037^{*}$ & 0.46 \\
Transfer of "moderate" member in stage S1 & 0.131 & 0.19 \\
Transfer of "most other-regarding" member in stage S1 & -0.094 & 0.08 \\
Constant & $0.615^{* *}$ & 0.20 \\
\hline Observations & 30 & \\
$\mathrm{R}^{2}$ & 0.08 & \\
\hline$* p<0.05 ; * p<0.01$ & &
\end{tabular}

In order to gain further insights into the driving forces behind a team's decision we resort to the contents of the chat protocols. On average, teams exchanged 22.3 messages (125 words) before reaching an agreement. ${ }^{11}$ However, the variance was rather large, with the shortest chat including only five messages with 18 words and the longest one including 58 messages with 353 words (see Appendix B for a translation of both). In Table 3 we list the arguments that have been voiced at least in two separate teams.

Table 3. Main arguments in the electronic team chat

\begin{tabular}{lccc}
\hline Argument & $\begin{array}{c}\text { Number of teams where } \\
\text { argument is discussed }\end{array}$ & $\begin{array}{c}\text { Relative frequency of } \\
\text { teams with argument }\end{array}$ & Average transfers \\
Keep more for ourselves & 22 & $73.3 \%$ & 0.51 \\
Fairness and ... & 11 & $36.7 \%$ & 0.52 \\
$\quad \ldots$ smaller transfers & 6 & $20.0 \%$ & 0.70 \\
$\quad \ldots$ higher transfers & 4 & $13.3 \%$ & 0.25 \\
Rationality & 2 & $6.7 \%$ & 0.00 \\
Economic expertise & &
\end{tabular}

The argument of sending small transfers in order to "keep more for ourselves" is voiced most often, namely in 22 out of 30 teams, and these teams send on average a transfer of $0.51 €$. This argument appeals to group identity by promoting a better outcome for the

\footnotetext{
${ }^{11}$ Neither the number of exchanged messages nor the number of words has any statistically significant impact on the team's transfer in stage S2.
} 
members of the team. It is never associated with the blunt claim that the team should behave selfishly.

The notion of "fairness" is mentioned in 17 out of 30 teams. However, it is used in two markedly different contexts. There are 11 teams in which remarks on fairness are actually used to support less generous transfers, and a typical argument is that "they [the recipients] can't expect us to send a fair share since they wouldn't do it either" (Team T5). These teams send on average $0.52 €$. In 6 teams the notion of fairness is put forward to induce more generous transfers or to prevent relatively small transfers. One example is that “... it's not fair to send only 20 cents, but we should send 1 euro" (Team T18). When fairness is mentioned in this context, the average transfer is $0.70 €$.

In 4 teams one member mentions that it would be "rational" to send a specific amount, without however defining rationality. Two subjects in different teams proposed zero transfers and justified their proposal by their "economic expertise".

In sum, the arguments put forward seem to support the observation that smaller rather than larger - transfers were the predominant social norm, often supported by arguments linked to payoff maximization or rational decision-making, as indicated in Table 3. Under these circumstances both PAT as well as SCT would, in fact, predict smaller transfers of teams than of individuals, which is what we actually observe.

Finally, we report in Table 4 data on the influence of gender and gender composition on chosen transfers. In stage S2 we distinguish between teams with a female majority (with at least two women) and those with a male majority. Please note that it was forbidden to reveal one's gender in the electronic chat of stage S2, which means team members were not aware of the other members' gender. 
Table 4. Average transfers and gender

\begin{tabular}{lccc}
\hline & $\begin{array}{c}\text { Stage S1 } \\
\mathbf{1}^{\text {st }} \text { individual transfer }\end{array}$ & $\begin{array}{c}\text { Stage S2 } \\
\text { Team transfer }\end{array}$ & $\begin{array}{c}\text { Stage S3 } \\
\mathbf{2}^{\text {nd }} \text { individual transfer }\end{array}$ \\
\hline Female / female majority & $0.78(N=38)$ & $0.56(N=12)$ & $0.53(N=38)$ \\
Male / male majority & $1.05(N=52)$ & $0.53(N=18)$ & $0.75(N=52)$ \\
\hline
\end{tabular}

Within a given stage, we never find any significant difference between decisions taken by female or male dictators, respectively by teams with a female or male majority. Our results corroborate previous findings of Andreoni and Vesterlund (2001) and Bolton and Katok (1995). Andreoni and Vesterlund (2001) have shown that gender differences in altruism depend on the price of other-regarding behavior, and if the price is unity (i.e. the benefits for the receiver equal the costs for the dictator), gender differences are not to be expected. Bolton und Katok (1995) have observed that those experiments revealing subjects' gender typically find significant gender effects, while studies without such information usually fail to report significant effects. The latter observation might account for the insignificant difference between male- and female-majority teams, as it was forbidden to reveal one's gender in our electronic chat. In the experiment of Dufwenberg and Muren (2006), however, the gender composition of teams was common knowledge, and female-majority teams allocated significantly higher amounts to the recipient.

\section{Conclusion}

Our experiment has shown that teams choose significantly smaller transfers than individuals in a dictator game and that individuals shift their transfers towards the team transfer when asked to make a second decision after team interaction. Hence, team decisions are more selfish than individual ones. This result is perfectly consistent with the large majority of experimental papers that have shown that team decisions are more selfish and competitive, less trusting and less altruistic than individual decisions (see, e.g., Bornstein and 
Yaniv, 1998; Bornstein et al., 2004; Cooper and Kagel, 2005; Cox, 2002; Cox and Hayne, 2006; Kocher and Sutter, 2005; Kugler et al., 2006). Therefore, we have been able to provide a further piece of evidence on the course of completing the emerging mosaic of team decision-making in economics. This piece of evidence is in contrast to Cason and Mui's (1997) results, though.

The differences between our findings and those of Cason and Mui (1997) might be explained by differences in the experimental design. First, Cason and Mui (1997) have controlled for the order of decision-making by having two treatments, one with the sequence "individual-team" decision-making, and another with the reverse order "team-individual". Yet, in both treatments teams are more altruistic than individuals. Therefore, our lack of a treatment where subjects start with team decision-making cannot have caused the difference. Recall also that individuals were not aware of the subsequent team stage when they decided in stage S1.

Second, Cason and Mui (1997) have used teams with two members whereas we have set up teams with three members. So far, there is little systematic variation of the size of teams in economic experiments and little evidence regarding its influence on team decisions. However, teams have been found to be more strategic and less altruistic both with two members (e.g., Cooper and Kagel, 2005), three members (e.g., Bornstein and Yaniv, 1998; Cox, 2002) or five members (Blinder and Morgan, 2005). Therefore, we are quite confident that the different team size is not the cause of the differences between our results and those of Cason and Mui (1997).

Third, and most important, in the experiment of Cason and Mui (1997) "every team was called to the front of the room (by identification numbers) and excused to the hallway to discuss their decision and fill out the form in private" (p. 1471). This procedure entails two important sources for the contrasting evidence. On the one hand, calling team members to the front of the room identifies the members of a team. Even though their decisions have 
remained anonymous in the experiment, the mere identification may have caused the higher transfers of teams. In fact, the evidence from Frey and Bohnet (1999) shows that transfers in the dictator game increase with identification of subjects (without revealing decisions). On the other hand, the teams in Cason and Mui's experiment used face-to-face discussion, whereas in our experiment team members interacted only via an electronic chat. Both approaches have their merits, but need not be neutral with respect to their influence on final decisions. The face-to-face design captures all facets of personal encounters when teams make decisions. However, the electronic chat-approach seems more suitable for studying the genuine effects of decision-making in teams as it provides a much more controlled environment by preserving anonymity and avoiding confounding factors like, for instance, personal sympathy or antipathy or prior acquaintance of team members unknown to the experimenter. The differences between both approaches might induce different degrees of social distance (within and across teams), which could trigger the different results. In fact, Kocher and Sutter (2006) have found first mover-teams in a gift-exchange game to act differently, depending upon whether team members have to reach a decision via face-to-face communication or via voting electronically on different proposals. When using the electronic form of communication, teams make more selfish decisions. ${ }^{12}$ The same mechanism could be the driving force behind the different findings in Cason and Mui (1997) and the current paper, meaning that there is no fundamental inconsistency between the two contributions. Obviously, the study of the effects of different communication media on team decision-making is an interesting area for future research on teams in economics.

\footnotetext{
${ }^{12}$ A somewhat related result can be found in Güth et al. (2006). They show in a large-scale newspaper experiment that (individual) decisions in a three-person ultimatum game are more selfish if submitted via Internet than via the more personal form of sending a letter.
} 


\section{References}

Andreoni, James and Ragan Petrie (2004): Public goods experiments without confidentiality: A glimpse into fund-raising. Journal of Public Economics 88, pp. 1605-1623.

Blinder, Alan S. and John Morgan (2005): Are two heads better than one? Monetary policy by committee. Journal of Money, Credit and Banking 37, pp. 789-812.

Bohnet, Iris and Bruno S. Frey (1999): Social distance and other-regarding behavior in dictator games: Comment. American Economic Review 89, pp. 335-339.

Bornstein, Gary, Tamar Kugler, and Anthony Ziegelmeyer (2004): Individual and group decisions in the centipede game: Are groups more "rational" players? Journal of Experimental Social Psychology 40, pp. 599-605.

Bornstein, Gary and Ilan Yaniv (1998): Individual and group behavior in the ultimatum game:

Are groups more "rational" players? Experimental Economics 1, pp. 101-108.

Bosman, Ronald and Frans van Winden (2002): Emotional hazard in a power-to-take experiment. Economic Journal 112, pp. 147-169.

Brosig, Jeannette, Martin G. Kocher and Matthias Sutter (2006): Bargaining among groups: The role of pre-play communication and the strategy method. University of Magdeburg. Working Paper.

Camerer, Colin F. (2003): Behavioral Game Theory: Experiments in Strategic Interaction. Princeton University Press, Princeton.

Cason, Timothy and Vai-Lam Mui (1997): A laboratory study of group polarization in the team dictator game. Economic Journal 107, pp. 1465-1483.

Cooper, David J. and John H. Kagel (2005): Are two heads better than one? Team versus individual play in signaling games. American Economic Review 95, pp. 477-509. 
Cox, James C. (2002): Trust, reciprocity, and other-regarding preferences: Groups vs. individuals and males vs. females. In: Zwick, R., Rapoport, A. (eds.), Advances in Experimental Business Research, pp. 331-350, Kluwer Academic Publishers, Dortrecht.

Cox, James. C. and Stephen C. Hayne (2006): Barking up the right tree: Are small groups rational agents? Experimental Economics 9, pp. 209-222.

Davis James (1992): Some compelling intuitions about group consensus decisions, theoretical and empirical research and interpersonal aggregation phenomena: Selected examples 1950 - 1990. Organizational Behavior and Human Decision Processes 52, pp. 3-38.

Dufwenberg, Martin and Astri Muren (2006): Gender composition in teams. Journal of Economic Behavior and Organization, forthcoming.

Fischbacher, Urs (1999): z-Tree - Zurich toolbox for readymade economic experiments experimenter's manual. Working Paper Nr. 21, Institute for Empirical Research in Economics, University of Zurich.

Güth, Werner, Rolf Schmittberger, and Bernd Schwarze (1982): An experimental analysis of ultimatum bargaining. Journal of Economic Behavior and Organization 3, pp. 367-388.

Güth, Werner, Carsten Schmidt, and Matthias Sutter (2006): Bargaining outside the lab: A newspaper experiment of a three-person ultimatum game. Economic Journal, forthcoming.

Forsythe, Robert, Joel Horowitz, Nathan Savin, and Martin Sefton (1994): Fairness in simple bargaining games. Games and Economic Behavior 6, pp. 347-69.

Kahnemann, Daniel, Jack Knetsch, and Richard Thaler (1986): Fairness as a constraint on profit seeking: Entitlements in the market. American Economic Review 76, pp. 728-41.

Kerr, Norbert, Robert MacCoun, and Geoffrey Kramer (1996): Bias in judgment: Comparing individuals and groups. Psychological Review 103, pp. 687-719. 
Kocher, Martin G. and Matthias Sutter (2005): The decision maker matters: Individual versus group behavior in experimental beauty-contest games. Economic Journal 115, pp. 200223.

Kocher, Martin G. and Matthias Sutter (2006): Individual versus group behavior and the role of the decision making procedure in gift-exchange experiments. Empirica, forthcoming.

Kugler, T., Gary Bornstein, Martin G. Kocher, and Matthias Sutter (2006): Trust between individuals and groups: Groups are less trusting than individuals but just as trustworthy. University of Arizona. Working Paper,

Levine, John and Richard L. Moreland (1998): Small groups. In: G. Fisher, G. Lindzey (eds.), The Handbook of Social Psychology, Vol. II, 4th Edition, pp. 415-469, Oxford University Press, Oxford.

Maciejovsky, Boris and David. V. Budescu (2005): Is cooperation necessary? Learning and knowledge transfer in cooperative groups and competitive auctions. University Illinois. Working Paper.

Moscovici, Serge and Marisa Zavalloni (1969): The group as a polarizer of attitudes. Journal of Personality and Social Psychology 12, pp. 125-135.

Rockenbach, Bettina, Abdolkarim Sadrieh, and Barbara Mathauschek (2006): Teams take the better risks. Journal of Economic Behavior and Organization, forthcoming.

Sutter, Matthias (2006): Team decision making under risk and myopic loss aversion. University of Cologne. Working Paper.

Sutter, Matthias, Martin. G Kocher, and Sabine Strauß (2005): Individuals and teams in UMTS-license auctions. University of Innsbruck. Working Paper. 


\title{
Appendix A: Experimental Instructions [not necessarily for publication;
}

\section{can be made public on the websites of the authors]}

\author{
Welcome to the experiment and thank you for your participation! \\ Please do not talk to other participants until the end of the experiment!
}

\section{Instructions}

The aim of this experiment is the investigation of economic decision behavior. During the experiment, you and the other participants will be asked to make decisions. You will earn money in doing so. The amount of your payoff is determined by your own decisions and by those made by the other participants.

\section{2 types of participants}

There are two types of participant: type A and type B. You will be randomly assigned to one of these types/roles.

\section{Duration}

The entire experiment will last for less than 60 minutes and consists of three separate stages that are completely independent of each other.

At the beginning of each stage you will receive detailed instructions for that stage. If you have any questions after reading the instructions, please raise your hand. One of the experimenters will come to you and answer your questions privately.

\section{Payoff}

Your earnings from all three stages will be added up and will be paid to you privately and in cash at the end of the experiment.

\section{Anonymity}

The identities of the participants that have interacted with you will never be revealed to you. The other participants will learn neither during nor after the experiment which role you were playing in and how much you have earned.

\section{Stage 1}

Each participant of type A is randomly matched with one participant of type B.

\section{Initial endowment}

Each participant of type A receives 5 EURO as his or her initial endowment.

Participants of type B do not receive an initial endowment.

\section{Decision participant A: Choice of a transfer}

Participant A specifies a transfer that determines which part of the initial endowment will be transferred from participant A to participant B. Each amount between and including 0 and 5 EURO (in 10 EURO-cent steps) can be selected.

This concludes stage 1 for participant A. You have to confirm your choice by pressing the $\mathrm{OK}$ Button.

Participant B cannot take any action in this stage.

\section{Results/earnings}

Earnings A = 5 Euro - Transfer

Earnings B = Transfer

Participant B will be informed of participant A's decision who he or she is paired with and of the resulting earnings only after the end of stage 3 . 


\title{
Stage 2 [handed out after completion of stage 1]
}

\section{Grouping}

You will be teamed up with two other participants of the same type. The structure of the experiment remains exactly the same as in stage 1. Your type remains the same as in the first stage.

The difference to the first stage is that now the three group members of type A have to agree on one collective decision concerning the transfer.

Each group of type A is randomly matched with one group of type B. Please note that the members of your matched group were not matched to you or any other member of your group in the previous stage.

Your decision in this stage of the experiment does not have any influence on the next stage.

\section{Initial endowment}

Each member of group A receives 5 EURO as initial endowment.

The members of group B do not receive an initial endowment.

\section{Decision group A: Choice of a transfer}

The members of group A have to agree on a transfer. A collective decision means that the three group members separately enter one identical number. This amount will be transferred from each member of group A to one member of group B.

Group communication will take place via electronic messaging (chat). Rules for the chat are specified below.

\section{Group B cannot take any action in this stage.}

\author{
Results/earnings \\ Earnings of EACH MEMBER of group A = 5 Euro - Transfer \\ Earnings of EACH MEMBER of group B = Transfer
}

Group B will be informed of group A's decision that they are paired with and of the resulting earnings only after the end of stage 3.

\section{Chat discussion rules}

If you are of type A, you are given the possibility to communicate with the two other members of your group to agree on a transfer - via electronic messaging (chat). The contents of communication is unrestricted, except that it is not permitted to reveal personal information like name, age, address, gender (please always use genderneutral formulations), field of study (including teachers, classes or contents, which would allow an identification of your field of study) or similar statements that lead to your identification (like your seat number in the lab). Furthermore, it is forbidden to use offensive language and to arrange side payments (i.e., rewards or punishments) of any kind. If you break these communication rules, the experimenters will exclude you from the experiment, and you will not receive any payoff for the entire experiment!

Each group member can send as many messages as he or she wants to the other two group members. Each message appears simultaneously on the screens of the other two members of your group. Selective messages to individual group members are not possible. As soon as the three group members agree on a transfer, they are requested to enter the amount of the transfer on their individual computer screen. Please note that the entries of all group members have to be identical in order to be valid. If this is not the case - or if team members have not entered a transfer after 10 minutes -earnings from this stage of the experiment will be zero for the group A. The transfer to group B would be determined randomly then.

\section{Stage 3 [handed out after completion of stage 2]}

Stage 3 is identical to stage 1 . Your task is exactly the same as in stage 1, and you will again make your decision individually. If you do not remember the rules from stage 1, please simply take a look at the instructions for stage 1 again. Please note that in this stage participants of type A are matched with another participant in the role of type $B$ than in stages 1 and 2.

\section{End}

This experiment ends after the third stage and you will be paid your overall earnings privately and in cash. Before being paid, we ask you to fill in a short questionnaire. 


\section{Appendix B: Two examples of the chat conversation}

The initial number in each line indicates a particular team member (1 to 3). Italic text at the end of a chat refers to the individual decisions in stages S1 and S3.

\section{B1. The most extensive discussion}

1:Obious decision, don't you think?

3: Sure, all for ourselves.

1: I am no good Samaritan.

3. Transfer: 0

3: right, neither am i

1 :we are not responsible for $b$, are we?

1: therefore 0

1: o.k. I'll enter it.

3: No. 2, do you share our opinion?

2: I think we should be fair

3: I don't. Nobody has ever been fair to me

1: 0 is fair

2: wait a second don't enter anything

3: next time you are $b$ and don't receive nothing

1: there's still the show up

2: that's a joke

3: I have also left once only with the show up

1: me too

3: I don't care about the show up....I vote for 0 !!!

2: what's this penny-pinching about?

2: we need a compromise

1: I still don't understand your point 2

3: yes, democracy! two against one

3: please 2, I have been the sucker too often. I am lucky this time and in the position to make some money

3: transfer $=0$ ?

2: You need those additional 2.5 so desperately?

3: to be honest: yes

$3: \ldots$ and I did not get those 2.5 too often

1: why should we give the money away?

3: why?

3: quick now, come on, please enter 0 ?

2: I don't want to play the upholder of moral standards, but I don't get your point. Compromise: 2

1: I enter 0

2: I enter 1.5

1: you can go on being nice after the experiment

3: great, we will all get nothing, are you aware of that?

3: you don' even know to whom you send the money!

2: just like b

2: 1.5

1: 0

3: apart from that, I am with No. 1: 2:1 for 0. please accept it No. 2!

2: hey, 1.5 is obliging

1: obliging....but completely useless

3: please 2 , hurry up and say 0

2: 1.5

2. ciao

3: what are you doing????

1: if we do not hurry up, we all will get nothing

3: 1 , what are you doing?

1: so, what?

3: 2 , what's the deal, that's impossible!!!!!!!!!!!!

2: 1.5 
$1: 1$ ?

2: ok

3: so, for heavens sake, make that 1 !

Individual transfers before team stage / after team stage:

1: $0 / 0$

2: $2.5 / 2.5$

$3: 2.5 / 0$

\section{B2. The shortest discussion}

2: I vote for 1 EURO transfer

1: that's ok

3: for me too

1: that's a fast decision

2: great

Individual transfers before team stage / after team stage:

1: $0.5 / 0.2$

2: $1 / 2.5$

$3: 1.5 / 0.5$ 